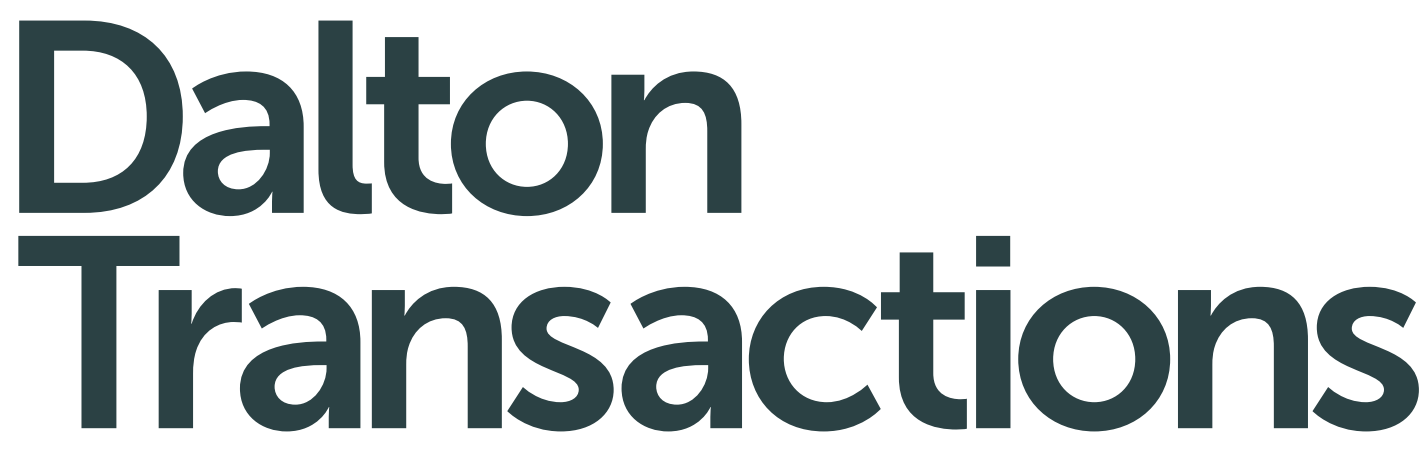

An international journal of inorganic chemistry www.rsc.org/dalton
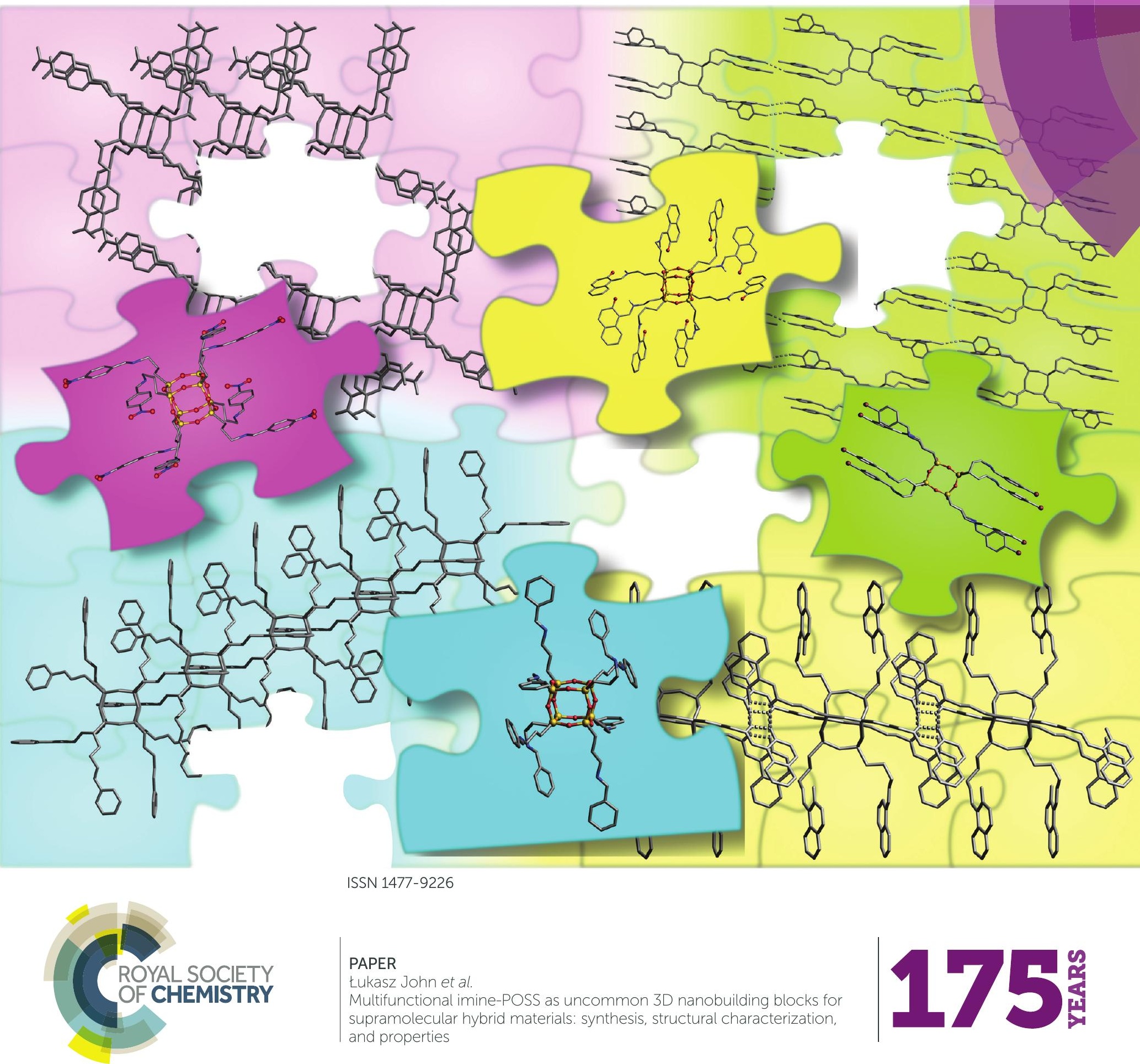

Multifunctional imine-POSS as uncommon 3D nanobuilding blocks for supramolecular hybrid materials: synthesis, structural characterization, and properties 


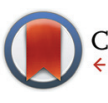

CrossMark \& click for updates

Cite this: Dalton Trans., 2016, 45 12312

Received 27th May 2016,

Accepted 23rd June 2016

DOI: $10.1039 / c 6 d t 02134 d$

www.rsc.org/dalton

\title{
Multifunctional imine-POSS as uncommon 3D nanobuilding blocks for supramolecular hybrid materials: synthesis, structural characterization, and properties $\uparrow$
}

\begin{abstract}
Mateusz Janeta, Łukasz John, * Jolanta Ejfler, Tadeusz Lis and Stawomir Szafert
In this article, we report on the chemistry and the spectroscopic properties of well-defined iminofunctionalized polyoctahedral oligomeric silsesquioxanes (imine-POSS) with various substitutions. Our efforts were mainly focused on side chains with sizable aryl groups possessing hydroxyl, nitro, and halide moieties. Such a choice enabled us to track their reduction abilities to secondary amine-POSS, tautomerization effects, and thermal properties. We also report for the first time the solid-state structures of five imino-functionalized cage-like octasilsesquioxanes. These structures provide unique examples of the complexities of three-dimensional packing motifs and their relationship with the assembly of tunable materials from nanobuilding blocks.
\end{abstract}

\section{Introduction}

Two- (2D) and three-dimensional (3D) structures have attracted great interest in the field of well-defined nanobuilding blocks (NBs). It mainly derives from the fact that altering the chemical composition of such NBs via refined synthetic tricks affects the possibility of creating sophisticated interactions between blocks allowing one to tailor global properties exactly at the finest length scales. ${ }^{1}$ Among the molecules that possess a high degree of symmetry, there are few examples of molecular compounds with functionalities and structures with a high 3D symmetry, such as tetraphenyladamantanes, ${ }^{2,3}$ dodecahedral boranes, ${ }^{4,5}$ cubanes, ${ }^{6,7}$ and tetrasilylmethane derivatives described in their early detailed work by Eaborn and Lickiss. ${ }^{8}$ The appearance of a cubic symmetry in octafunctionalized and three-dimensional units, in combination with an appropriate choice of functionality, is particularly desirable to facilitate the assembly of functional materials. ${ }^{9-12,40}$

The structural and physico-chemical properties as well as the potential applications of polyoctahedral oligomeric silsesquioxanes (POSS) are directly related to the precisely designed organic side chains attached to the siloxane cage-like core.

Faculty of Chemistry, University of Wroctaw, 14 F. Joliot-Curie, 50-383 Wroctaw, Poland.E-mail: lukasz.john@chem.uni.wroc.pl; Fax: +(48) 713282348

$\dagger$ Electronic supplementary information (ESI) available: The details of synthetic steps and the characterization data, $\left({ }^{1} \mathrm{H},{ }^{13} \mathrm{C},{ }^{29} \mathrm{Si}\right) \mathrm{NMR}$, FTIR, HR-MS, EDS, UV-Vis spectra, TG-DTA, DSC, PXRD and X-ray data. CCDC 1456557-1456561. For ESI and crystallographic data in CIF or other electronic format see DOI: 10.1039/c6dt02134d
Cubic silsesquioxanes constitute a group of organosilicon compounds with the chemical formula $\left(\mathrm{RSiO}_{3 / 2}\right)_{8}$ (where $\mathrm{R}$ is $\mathrm{H}$, alkyl, aryl, etc.). Their attractiveness is due to the fact that various $\mathrm{R}$ substituents can be effectively anchored to the silicon atom (Fig. 1). Covalently bonded organic arms make reactive functionalities suitable for polymerization or grafting. This makes POSS unusual because they establish an inorganic silicate core and an organic outer sphere. Such a structure can simply affect rigidity, thermal stability, hydrophobicity, and other remarkable properties. Within the class of cage-like organosilicons such as $T_{6}, T_{8}, T_{10}$, and $T_{12}$ considerable attention is focused on $\mathrm{T}_{8}$ cages, which are the most widely studied. ${ }^{13}$ POSS nanostructures have diameters in the range of 1-3 nm and, hence, may be considered as the smallest existing silica particles. POSS particles have been classified as having a zerodimensionality; however, they have the ability to create higher dimensionalities (1, 2 or 3D building blocks) through the functionality of side chains. ${ }^{14}$

Octafunctionalized POSS can be obtained via the hydrolytic condensation of trifunctional silane compounds, including

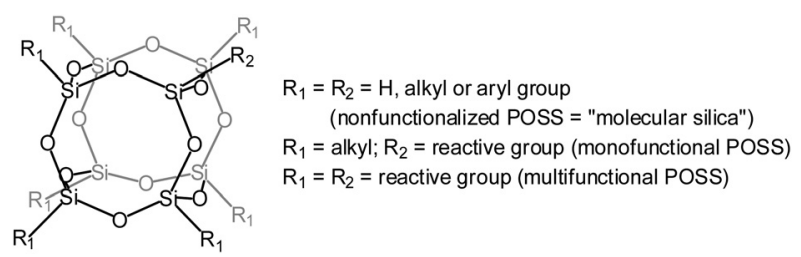

Fig. 1 Types of octameric $\left(T_{8}\right)$ POSS. 


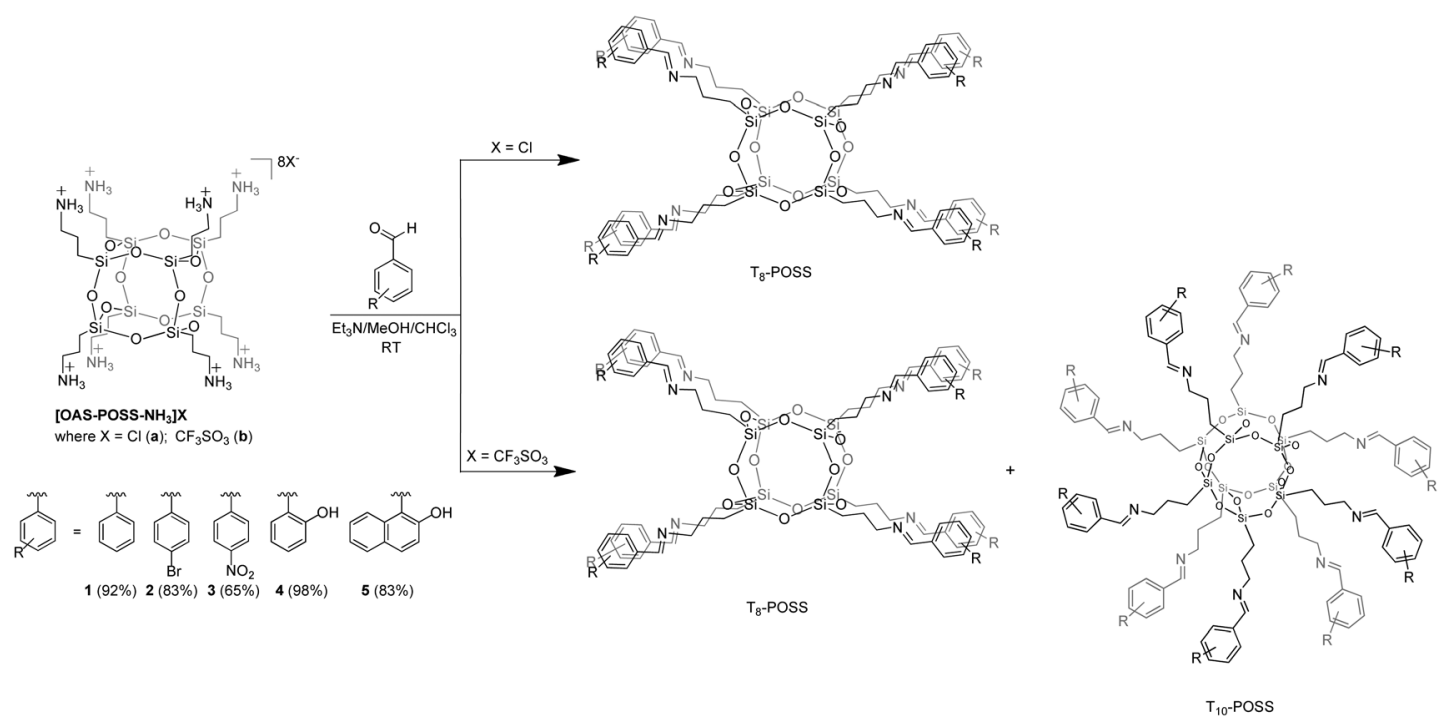

Scheme 1 Synthesis of imino functionalized-POSS 1-5.

chloride, alkoxo, and acetoxy derivatives, by using base or acid catalysts. Because the yields of such reactions are usually low, it is better to synthesize these species in two steps: (i) synthesis of POSS as the starting materials, and then (ii) chemical functionalization of their arms. These reactions should be chosen in such a way as to avoid cagerearrangements.

Functionalized POSS with attractive properties are successfully used in various areas of chemistry, and many interesting examples that illustrate them have already been described. ${ }^{13}$ For example, systems based on cage-like silsesquioxanes have been intensively examined in photonics and electronic devices. ${ }^{15-18}$ Phthalimide and $o$-sulfobenzimide-functionalized silsesquioxanes have been found to be promising materials for the further functionalization of other nitrogen-based POSS. ${ }^{19}$ Tetraphenyl silsesquioxanes based on covalent-organic frameworks are reported to be efficient hydrogen storage materials. ${ }^{20}$ Shape and confinement effects on the supramolecular interactions of hydrogen-bonded bent-core liquid crystals based, inter alia, on POSS systems have also been studied for various terminal siloxane groups. ${ }^{21}$ Laine et al. reported on crystalline hybrid polyphenylene macromolecules derived from octaalkynylsilsesquioxanes as a potential synthetic approach to threedimensional graphenes. ${ }^{17}$ The above-discussed materials constitute only a handful of examples of their potential applications in chemistry and industry. Imino-functionalized polyoctahedral oligomeric silsesquioxanes comprise a less explored group of modified POSS. Jones et al. synthesized and structurally characterized $\mathrm{Al}(\mathrm{III})^{22}$ and $\mathrm{Zn}(\mathrm{II})^{23}$ POSS complexes and reported on their use for the ring opening polymerization of rac-lactide. In these studies, the imine-POSS ligands were prepared by the reaction of the non-fully condensed siloxanetriol $\left(1,3,5,7,9,11,14\right.$-heptaisobutyltricyclo[7.3.3.1 ${ }^{5,11}$-heptasiloxane-endo-3,7,14-triol) with $(\mathrm{MeO})_{3} \mathrm{Si}\left(\mathrm{CH}_{2}\right)_{3} \mathrm{NH}_{2}$ in $\mathrm{MeOH}$ to form non-symmetric silsesquioxanes containing one amino- propyl group. To our best knowledge, there are only two known examples of cage-like silsesquioxanes in which only one side group (so-called monofunctional POSS) possesses an imine fragment. ${ }^{22,23}$ At the same time, there are no papers describing the chemistry or the synthetic aspects concerning imino-octafunctionalized POSS (so-called multifunctional POSS). In this article, we report the synthesis, characterization, and structural investigations of novel polyoctahedral oligomeric silsesquioxanes fully functionalized with the imine side chains ( $\mathrm{T}_{8}$-type imine-POSS) in the post synthetic modification of POSS (Scheme 1).

\section{Results and discussion}

\section{Synthesis and characterization of 1-5}

Looking for a stable cage scaffold for the further preparation of octa-imino-functionalized POSS derivatives, in the first thrust we obtained two OAS-POSS-based salts, [OAS-POSS-NH $\mathrm{N}_{3}$ ] $\mathrm{Cl}$ (a), and [OAS-POSS- $\left.\mathrm{NH}_{3}\right] \mathrm{CF}_{3} \mathrm{SO}_{3}(\mathbf{b})$, as shown in Scheme 2. Based on a previously reported method, ${ }^{24}$ octa(3-aminopropyl) silsesquioxane salts were obtained in a one-step hydrolytic condensation using commercially available (3-aminopropyl)

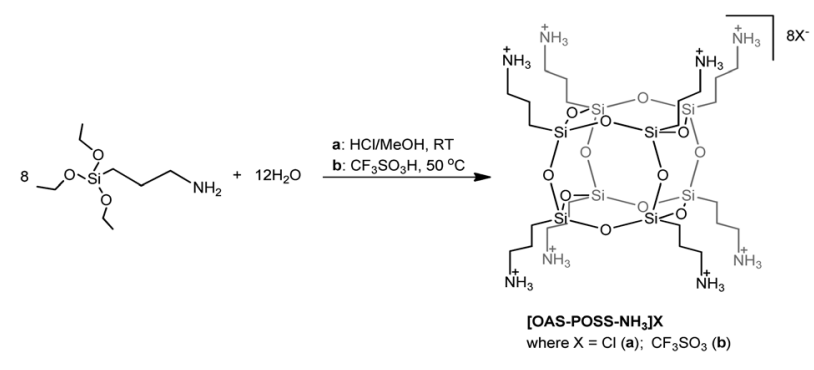

Scheme 2 Synthesis of [OAS-POSS- $\left.\mathrm{NH}_{3}\right] \mathrm{X}$. 
triethoxysilane and an appropriate amount of $\mathrm{HCl}$ or $\mathrm{CF}_{3} \mathrm{SO}_{3} \mathrm{H}$. Because of the low stability of cage-like silsesquioxanes containing aminopropyl groups (they are stable only in dry methanol at $-8{ }^{\circ} \mathrm{C}$ for a short time), ${ }^{25}$ we used its airstable chloride or trifluoromethanesulfonate salts for further modification.

The above-mentioned imino-functionalized derivatives 1-5 were obtained with high yields, using octa(3-aminopropyl)silsesquioxane hydrochloride (OAS-POSS-Cl) or triflate (OAS-POSS- $\mathrm{CF}_{3} \mathrm{SO}_{3}$ ), an appropriate aldehyde, and triethylamine as a deprotonation agent as shown in Scheme 1. Reactions were conducted at room temperature. We noticed that in the case of imine-POSS, a higher reaction temperature affects the partial decomposition of the siloxane cage.

Compounds 1-5 were isolated by flash chromatography and characterized by ${ }^{1} \mathrm{H},{ }^{13} \mathrm{C}$, and ${ }^{29} \mathrm{Si}$ NMR spectroscopy. In solution, molecules of 1-5 possess an idealized $O_{\mathrm{h}}$ symmetry, which is manifested in NMR spectra by sets of symmetry-equivalent signals of the side chains. For example, in the ${ }^{1} \mathrm{H}$ NMR spectrum of $\mathbf{1}$, only one characteristic signal of the imine group at $\delta=8.31 \mathrm{ppm}$ was observed. Moreover, the presence of the iminopropyl group $(-\mathrm{N}=\mathrm{CH})$ was evidenced by a single resonance at $161.0 \mathrm{ppm}$ in the ${ }^{13} \mathrm{C}$ NMR spectrum. The chemical shift of the ${ }^{29} \mathrm{Si}$ NMR signal is within the expected region for alkyl-substituted cubic POSS $^{26}$ at -66.5 ppm as a single, symmetrical signal, which confirmed the presence of only one type of silicon nucleus.

The mass spectrum (Fig. 2) also clearly confirmed the formation of a closed frame structure composed of eight silicon atoms possessing terminal alkyl-imine side chains. Moreover, the presence of siloxane fragments was confirmed (see the Experimental section in ESI $\dagger$ ) based on FT-IR studies $\left(\nu_{\mathrm{Si}-\mathrm{O}-\mathrm{Si}}=1112 \mathrm{~cm}^{-1}\right)$.

The substitution of all amine arms in OAS-POSS was unambiguously verified by high-resolution mass spectrometry (see

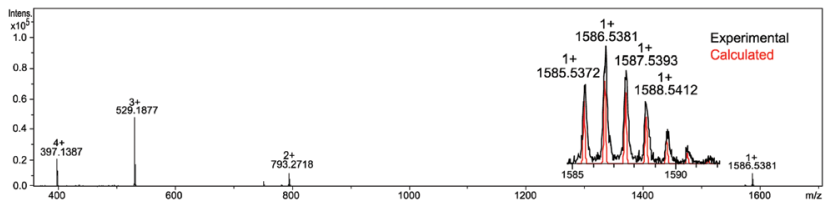

Fig. 2 HR-MS spectra of 1.
ESI, Fig. S57-S66†). In the case of 3, the formation of side products, i.e. not fully octa-substituted compounds such as hepta$\mathrm{T}_{8} \mathrm{R}_{7}$ and hexa- $\mathrm{T}_{8} \mathrm{R}_{6}$ derivatives (Fig. 3) was observed and confirmed by HRMS. Not fully substituted derivatives were separated using flash chromatography.

\section{Cage-rearrangement}

In the reaction of OAS-POSS- $\mathrm{CF}_{3} \mathrm{SO}_{3}$ with an aldehyde, we observed the cage-rearrangement reaction. The obtained products were identified by high-resolution mass spectrometry. Also the NMR spectra indicated the formation of two compounds. In the ${ }^{1} \mathrm{H}$ NMR spectra, the signals at $\delta=8.23$ and 8.19 ppm can be assigned to two different imine $\mathrm{CH}=\mathrm{N}$ groups (see ESI, Fig. S24 $\dagger$ ). Besides, in the ${ }^{29} \mathrm{Si}$ NMR spectra, two signals localized at $\delta=-66.5 \mathrm{ppm}$ (identified for 1 with $O_{\mathrm{h}}$ symmetry) and at $-68.7 \mathrm{ppm}$ (typical of POSS possessing $D_{5 \mathrm{~h}}$ geometry) were observed, which confirmed the formation of the $\mathrm{T}_{10}$ product (Fig. 4).

The presence of the $\mathrm{CF}_{3} \mathrm{SO}_{3}{ }^{-}$anion in the reaction mixture causes the cage-rearrangement of the silsesquioxane core, whereas $\mathrm{H}_{2} \mathrm{O}$ is formed during the reaction of imines. Such reactivity confirms the previously described mechanism ${ }^{27}$ concerning $\mathrm{T}_{8} \rightarrow \mathrm{T}_{10}$ cage-rearrangement using the $\mathrm{CF}_{3} \mathrm{SO}_{3}{ }^{-} / \mathrm{H}_{2} \mathrm{O}$ system (Scheme 3). The formation of $\mathrm{T}_{8}, \mathrm{~T}_{10}$, and $\mathrm{T}_{12}$ from $\left(\mathrm{PhSiO}_{1.5}\right)_{8}$ catalyzed by $\mathrm{F}^{-}$was also observed by Laine et al. ${ }^{28}$ Ervithayasupor $^{29}$ also observed the reorganization of octakis(3chloropropyl)silsesquioxane through nucleophilic substitutions using sodium 4-substituted phenoxide, sodium acrylate, ${ }^{30}$ or potassium phthalimide ${ }^{19}$ that led to the formation of a $\mathrm{T}_{8}, \mathrm{~T}_{10}$, and $\mathrm{T}_{12}$ mixture.

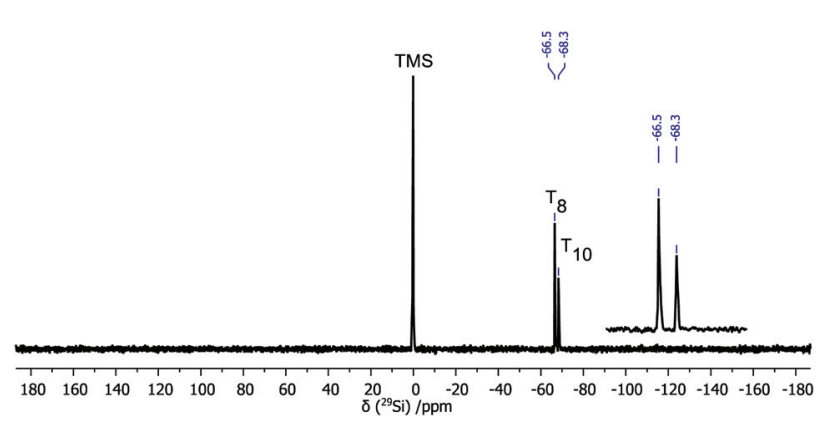

Fig. $4{ }^{29} \mathrm{Si}\left(59.6 \mathrm{MHz}, \mathrm{CDCl}_{3}\right)$ NMR spectrum of the product of the reaction of OAS-POSS- $\mathrm{CF}_{3} \mathrm{SO}_{3}$ with benzaldehyde.
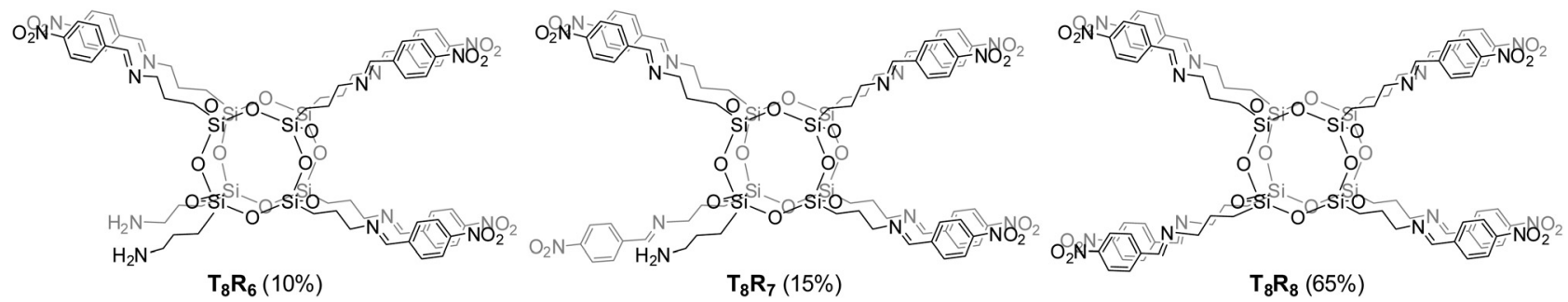

Fig. 3 Products identified during the reaction of 4-nitrobenzoic aldehyde with OAS-POSS-Cl. 


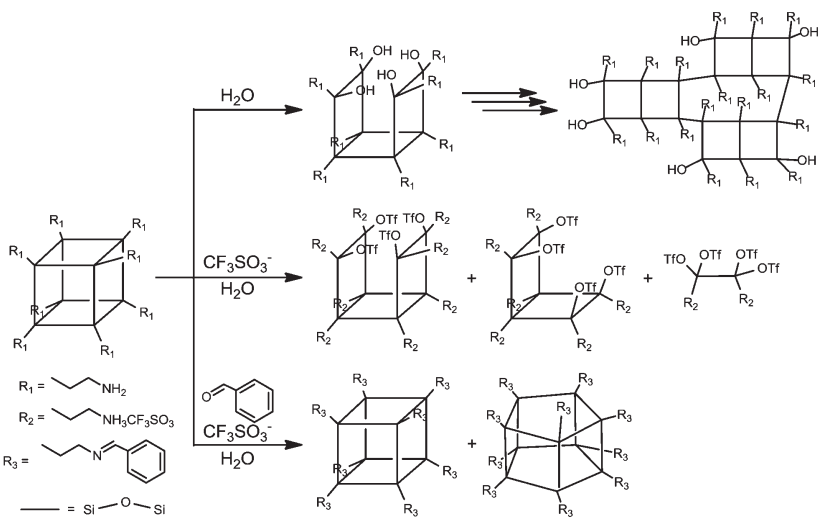

Scheme 3 Synthesis of $\mathrm{T}_{10}$ forced by cage-rearrangement in the presence of $\mathrm{CF}_{3} \mathrm{SO}_{3}{ }^{-} / \mathrm{H}_{2} \mathrm{O}$.

\section{Solid-state structures of imine-POSS}

Compounds 1-5 were characterized in the solid state by IR spectroscopy and by single-crystal X-ray diffraction analysis. Careful analysis of the collected data revealed that imine-POSS crystallizes in the triclinic system and the centrosymmetric $P \overline{1}$ space group. The asymmetric unit is composed of four silicon atoms and four organic side chains, which are directly bonded to $\mathrm{Si}$ atoms to form a $\mathrm{T}_{8}$-like siloxane core. The molecule possesses a cubic $\mathrm{Si}_{8} \mathrm{O}_{12}$ framework with the imine groups attached to each silicon atom through $n$-propyl carbon chains. The Si atoms are substantially tetrahedral and surrounded by three oxygen atoms that create a silsesquioxane core made of Si-O bonds. Their molecular structure is shown in Fig. 5. For $\mathbf{1 - 5}$, the core geometry is similar. The silicon atoms tend to keep a tetrahedral geometry, which causes the oxygen atoms to point outwards from the cube edges. Additionally, the steric ramification of the side chains connected to silicon atoms also strongly contribute to distortion. Nevertheless, all data of the core are in the standard range for $\mathrm{T}_{8}$-like silsesquioxanes: O-Si-O angle, $107-112^{\circ}$; Si-O-Si angle, $145-152^{\circ}$; $\mathrm{Si}-\mathrm{O}$ bond, 1.55-1.65 $\AA^{31}$ For 1, the $\mathrm{C}(4)-\mathrm{N}$ bond length is 1.265(7) $\AA$, close to that characteristic of $\mathrm{C}=\mathrm{N}, 1.279 \AA$, which supports the presence of an imine bond and occurs in the $E$-configuration (like for 2-5). The selected bond distances and angles for all the above compounds are given in Table 1 (for more details see also ESI, Tables S1-S14, $\dagger$ and the CIF files).

As can be seen in Fig. 5 and after a careful analysis of the $\mathrm{Si}-\mathrm{O}$ bond lengths, it can be noticed that the $\mathrm{Si}_{8} \mathrm{O}_{12}$ core is "overstretched". This is due to the steric hindrance of the organic-chains that repel lengthening of the sides of the cube. This phenomenon can be observed by analyzing the distance between the silicon atoms located at the polyhedral corners. This is also confirmed by infrared spectroscopy, where the absorption band derived from the vibration of the $\mathrm{Si}-\mathrm{O}-\mathrm{Si}$ mode is extended and not fully symmetrical (Fig. 6). In the IR spectrum of $\mathbf{4}$, in which this deformation is the most noticeable, two overlapping bands are present in the area of the stretching vibration of the $\mathrm{Si}-\mathrm{O}-\mathrm{Si}$ moiety which are derived from the two sides of the rectangle forming the prism. In turn,
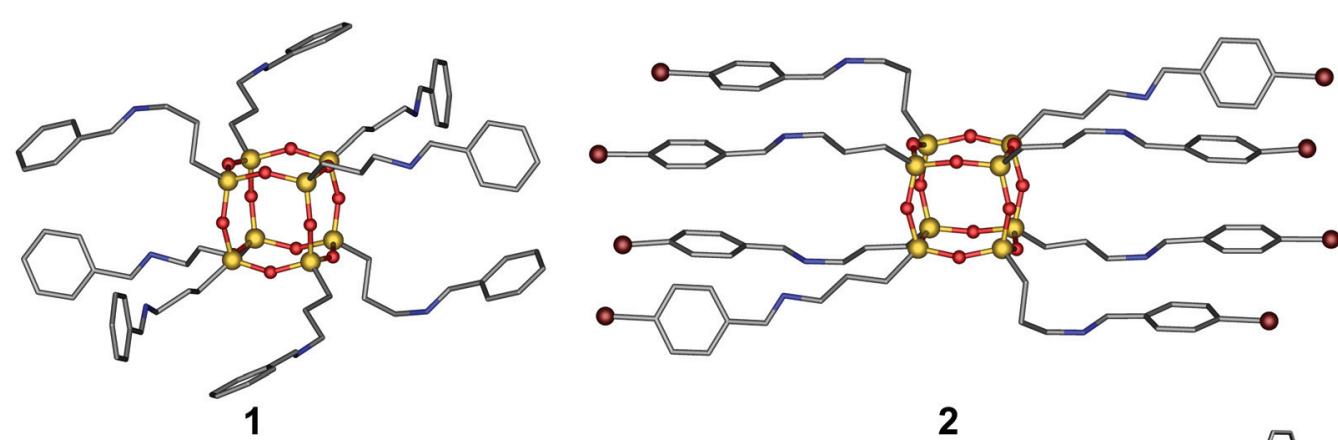

2

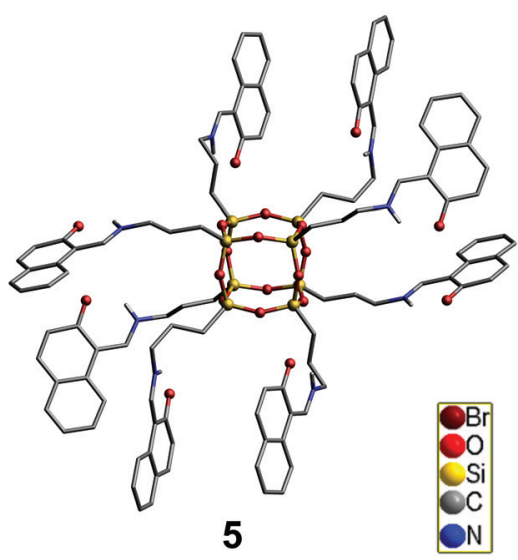

Fig. 5 Molecular structures of 1-5. 
Table 1 Selected bond distances $(\AA)$ and angles $\left({ }^{\circ}\right)$ for 1-5

\begin{tabular}{|c|c|c|c|c|c|c|c|c|}
\hline & \multicolumn{2}{|c|}{ Mean Si-O } & \multicolumn{2}{|c|}{ Mean $\mathrm{Si}-\mathrm{O}-\mathrm{Si}$} & \multicolumn{2}{|l|}{$\mathrm{O}-\mathrm{Si}-\mathrm{O}$} & \multicolumn{2}{|c|}{ "Mean trans $\mathrm{Si} \cdots \mathrm{Si} " a$} \\
\hline & $\begin{array}{l}\text { Average } \\
\text { value }\end{array}$ & Range of values & $\begin{array}{l}\text { Average } \\
\text { value }\end{array}$ & Range of values & $\begin{array}{l}\text { Average } \\
\text { value }\end{array}$ & Range of values & $\begin{array}{l}\text { Average } \\
\text { value }\end{array}$ & Range of values \\
\hline 1 & 1.6228 & $1.6180-1.6271$ & 148.26 & $145.48-150.07$ & 109.03 & $108.46-109.40$ & 5.400 & $5.391-5.412$ \\
\hline 2 & 1.620 & $1.612-1.626$ & 148.89 & $143.04-152.45$ & 108.10 & 108.14-109.79 & 5.403 & $5.387-5.433$ \\
\hline 3 & 1.624 & $1.617-1.628$ & 148.55 & $144.77-152.96$ & 108.97 & $108.28-109.45$ & 5.412 & $5.405-5.428$ \\
\hline 4 & 1.6249 & $1.6206-1.6314$ & 147.29 & $143.90-152.46$ & 109.10 & 108.39-109.76 & 5.399 & $5.375-5.415$ \\
\hline 5 & 1.6220 & $1.615-1.628$ & 148.89 & $148.37-150.1$ & 109.23 & 108.56-109.76 & 5.413 & $5.401-5.421$ \\
\hline
\end{tabular}

${ }^{a}$ The term "Mean trans Si...Si" refers to non-bonding distances between the silicon atoms lying at the opposite corners of the siloxane core.

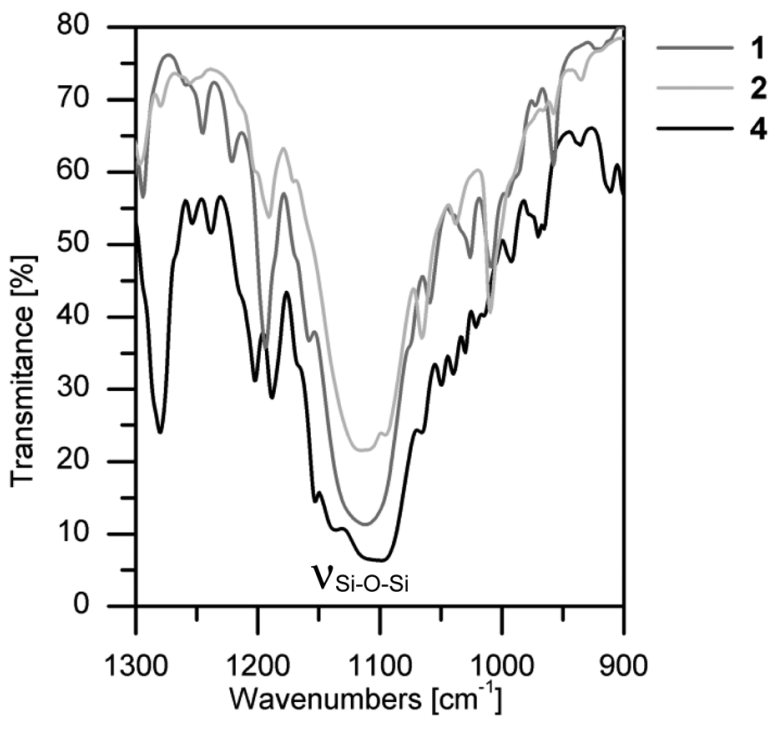

Fig. 6 FT-IR spectra of 1, 2, and 4 .

for $\mathbf{1}$ and $\mathbf{5}$, which possess the smallest deformation, only one symmetrical narrow band is noticed.

Such an elongation of the core occurs in the solid state, whereas in solution, based on the ${ }^{29} \mathrm{Si}$ NMR spectrum, only one signal $(\delta=-66.7 \mathrm{ppm})$ originating from the core is observed, and it can be concluded that in solution all the silicon atoms are equal and symmetrically identical. In the case of 2, the non-binding distances between the silicon atoms are in the 5.387-5.433 $\AA$ range, which constitutes the widest range among the imine-POSS presented in this paper, and the deformation of the Si core is the most pronounced. Based on the values of non-binding $\mathrm{Si} \cdots \mathrm{Si}$ distances along the same axis, the dimension of the cage was evaluated and equals $3.074 \times 3.133 \times 3.148 \AA$. In this case, the siloxane core geometry seems cuboid-like rather than a cube. Thanks to the halogen bonds, the deformation of the core is related to the repulsion of side chains, which are arranged strictly parallel to each other.

\section{Investigations on the supramolecular structures of 1-5}

A detailed analysis of the crystal structures of 1-5 revealed that the POSS clusters self-assemble through complementary specific noncovalent interactions to produce an extended 3D network. The structure of $\mathbf{1}$ revealed that the POSS clusters self-assemble via $\mathrm{CH}_{\mathrm{Ar}} \cdots \mathrm{CH}, \mathrm{CH}_{\mathrm{Ar}} \cdots \mathrm{N}$, and $\mathrm{CH}_{\mathrm{Ar}} \cdots \mathrm{O}$ interactions leading to the $3 \mathrm{D}$ grid (Fig. 7). The values of the hydrogen bonds are summarized in Table S3.†

We also investigated the effect of bromo and nitro substituents at the para-position of the phenyl ring on the supramolecular structure evolution and explored whether they could be used for further modification of the packing mode of the resulting noncovalent materials. The organic arms in 2 (Fig. 8) are in the shape of a tube through which there are four chains which repel each other on each side, thereby increasingly affecting the sides of the POSS. In the crystal structure of 2, type I halogen bonds occur between bromines, $\mathrm{Br} \cdots \mathrm{Br}$ contacts being 3.540 and $3.497 \AA$ (5.5\% below the van der Waals sum); there are also $\mathrm{Si} \cdots \mathrm{Br}(3.867 \AA, 2.1 \%$ below the van der Waals sum) short contacts. Thanks to their occurrence and the introduction of a propyl spacer, compound 2 takes the form of a "cylinder" with a $C_{2 \mathrm{v}}$ symmetry. It is worth noting that the existence of such a geometry has not yet been observed for functionalized POSS species in the solid state. Also Laine et $a l .{ }^{32}$ reported the presence of a halogen bond for iodinated and brominated octaphenylsilsesquioxanes; these derivatives create type I and type II halogen bonds that result in totally different star-like branched molecular structures of the resulting POSS.

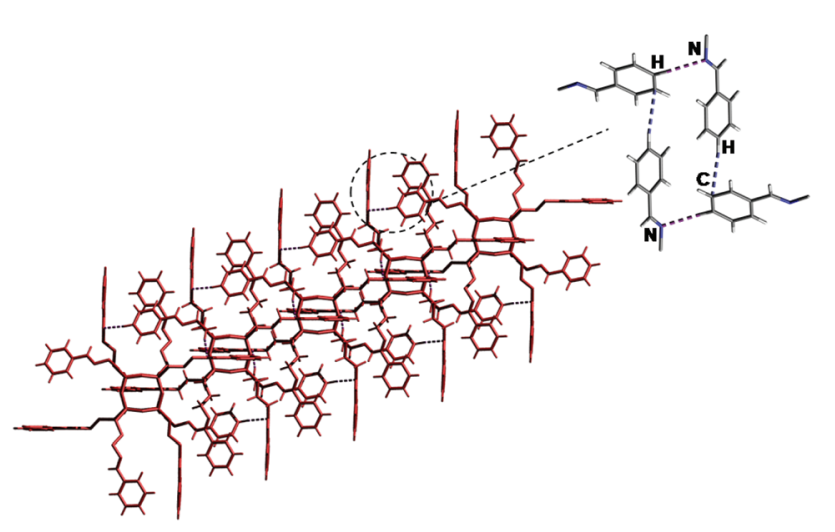

Fig. 7 View of the supramolecular arrangement in a 3D grid of 1 along the $b$ axis. The violet dotted lines represent $\mathrm{CH}_{\mathrm{Ar}} \cdots \mathrm{N}$ interactions; the blue ones represent $\mathrm{CH}_{\mathrm{Ar}} \cdots \mathrm{C}$ interactions. 


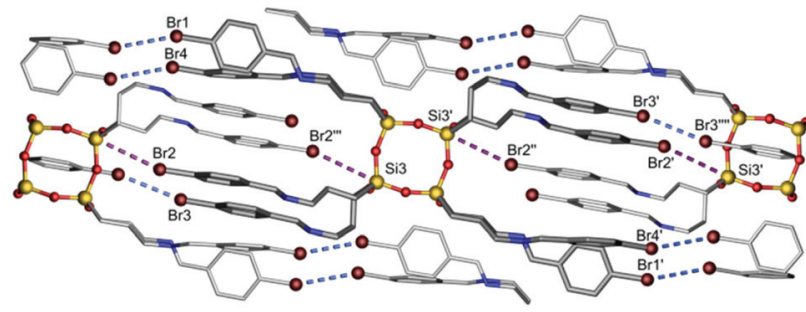

Fig. 8 View of the supramolecular arrangement in a 3D grid of 2 along the $b$ axis. The blue dotted lines represent $\mathrm{Br} \cdots \mathrm{Br}$ interactions, the violet dotted lines represent $\mathrm{Si} \cdots \mathrm{Br}$ interactions. Symmetry codes: ' $2-x,-y$, $-z, " 1+x, y,-1+z, " ' 1-x,-y, 1-z, " ' 2+x, y-1+z$.

A detailed analysis of the crystal structure of 3 shows that the hierarchical self-organization steps of these units driven by a combination of noncovalent interactions lead to the formation of a 3D supramolecular network. The first level selfassembly process comprises the docking of four parent molecules of 3 that are held together by $\mathrm{N} \cdots \mathrm{O}$ and $\mathrm{O} \cdots \mathrm{C}_{\mathrm{Ar}}$ interactions, which results in the formation of a noncovalently bonded grid, as illustrated in Fig. 9. These "secondary building modules" are further organized through a subsequent selfassembly process induced by $\mathrm{C}-\mathrm{H} \cdots \mathrm{O}, \mathrm{N} \cdots \mathrm{O}$, and $\mathrm{CH} \cdots \mathrm{HC}$ interactions into an extended layered close-packed 3D structure with gated voids. On the basis of PLATON calculations, the free voids in 3 are estimated to constitute $20 \%$ of the unit cell volume and are filled by four molecules of chloroform. Guest molecules are trapped in the channels formed by the imine side chains. These channels connect the two corners of the unit cell. The quantity of solvent molecules was confirmed by TG studies conducted on separate single crystals. Data on the geometry of the hydrogen bonds and the close contacts are collected in Table S8. $\uparrow$ After removal of the solvent from the crystal lattice, on the PXRD pattern of 3 can be observed new

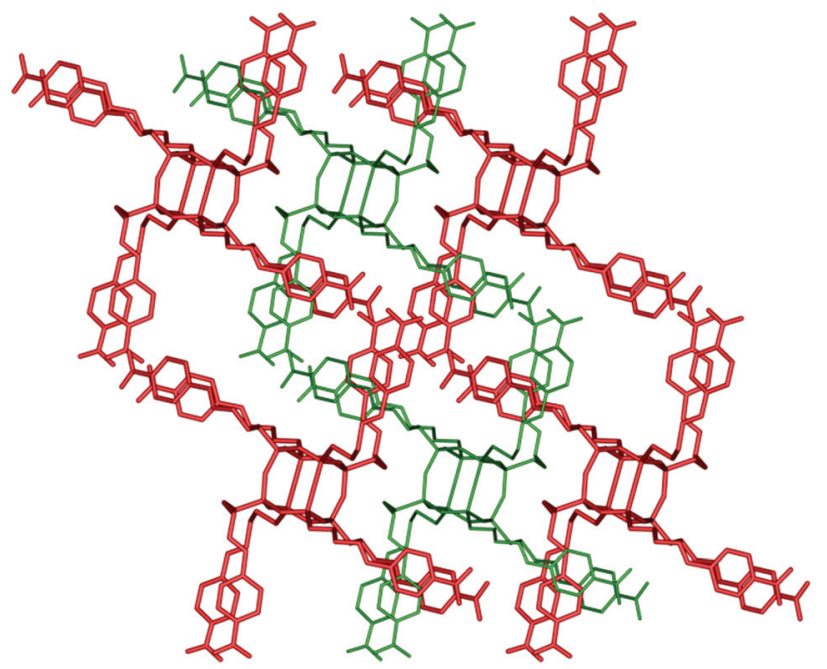

Fig. 9 View of the 3D interpenetrated network in the crystal structure of 3 along the $b$ axis. Chloroform molecules are trapped in the free space. diffraction peaks at $2 \theta=7.47,11.54$, and $22.86^{\circ}$, that can indicate the formation of additional phase(s).

The Schiff bases from the group of salicylideneimine constitute some of the well-known compounds in which the thermochromism phenomenon is observed. Earlier studies have shown that this phenomenon is closely related to tautomeric equilibria. ${ }^{33}$ This might be explained by the presence of an imine-enamine tautomerism between the $\mathrm{OH}$ and the $\mathrm{NH}$ forms that occur in the compound and the stabilization of the $\mathrm{NH}$ form that is extorted by the intermolecular hydrogen bonds. Both forms coexist and stay in equilibrium in the crystalline form, and the observed structure is a superposition of the two tautomers.

It has been found that $\mathbf{4}$ appears in the $\mathrm{OH}$ form, and the average $\mathrm{C}-\mathrm{O}$ bond length is $1.351 \AA$ and stays in the range of the $\mathrm{C}-\mathrm{O}$ bond length for phenol rings $(1.360 \AA)$. The bond length of C(4)-N, in turn, equals 1.280(5) $\AA$ and is close to that characteristic of $\mathrm{C}=\mathrm{N}, 1.279 \AA{ }^{34}$ which testifies the existence of enol-imine tautomerism. The supramolecular arrangement of 4 is created by short interactions (e.g. $\mathrm{CH}_{2} \cdots \mathrm{O},=\mathrm{CH} \cdots \mathrm{CH}$, $\mathrm{Si} \cdots \mathrm{O}, \mathrm{CH}_{2} \cdots \mathrm{Si}, \mathrm{CH} \cdots \mathrm{O} ;<1 \%$ below the van der Waals sum) and a strong $\mathrm{O} 1-\mathrm{H} 1 \cdots \mathrm{N} 1$ intramolecular hydrogen bond.

The geometry of 5 corresponds to the $\mathrm{NH}$ form (Fig. 5); however, it is different from that expected for a typical ketoenamine form. The C6-O1 (1.245-1.326 ̊) and C4-C5 (1.389-1.414 $\AA$ ) bonds are longer compared to ordinary bonds expected for enol-like compounds, $\mathrm{C}=\mathrm{O}(1.222 \AA)$ or $\mathrm{C}=\mathrm{C}$

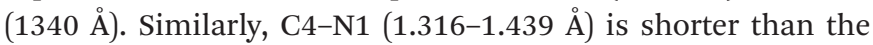
$\mathrm{C}\left(\mathrm{sp}^{2}\right)-\mathrm{N}$ bond characteristic of enamines (1.355 $\left.\mathrm{A}\right)$. This may suggest that 5 possesses a zwitterionic form. This results in a significant reduction of the melting point $\left(78^{\circ} \mathrm{C}\right)$ compared with the salicylidene derivative of $4\left(124^{\circ} \mathrm{C}\right)$, in which the above-mentioned phenomenon was not observed. The two tautomeric forms may interchange through an intramolecular hydrogen bond $(\mathrm{C}=\mathrm{O} \cdots \mathrm{HN})$. Compound $\mathbf{5}$ crystallizes as a methanol solvate. Methanol molecules are arranged between the naphthalene rings of the side chains and create channels by means of hydrogen bonds (Fig. 10).

Imine-POSS also constitutes a perfect example for which a self-assembly protocol can be discussed, as was confirmed for one of the resulting imine-POSS, 2, containing a Br-substituted ring. The so-called self-assembled morphology is forced by a

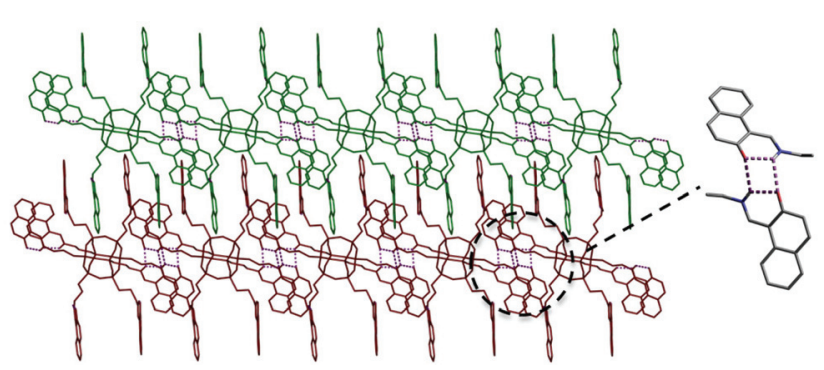

Fig. 10 View of the 3D network in the crystal structure of 5 along the $a$ axis showing the intra- and intermolecular $\mathrm{NH} \cdots \mathrm{O}$ hydrogen bonds (purple dotted lines). Methanol molecules are omitted for clarity. 

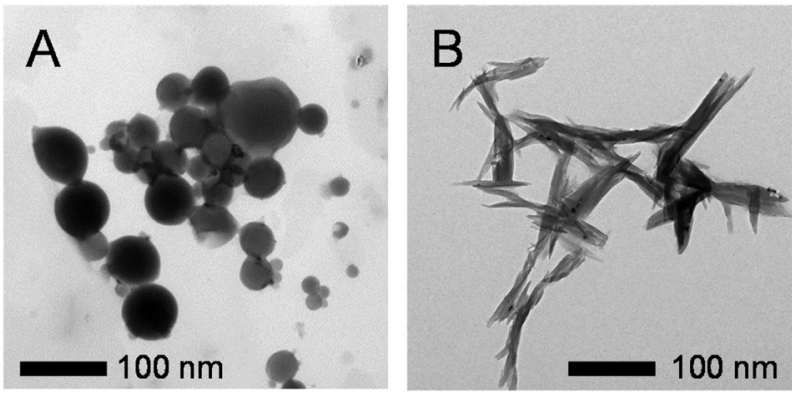

Fig. 11 Selected HR-TEM images of 2 isolated from $\mathrm{CHCl}_{3}(\mathrm{~A})$ and $\mathrm{MeOH}$ (B) solutions.
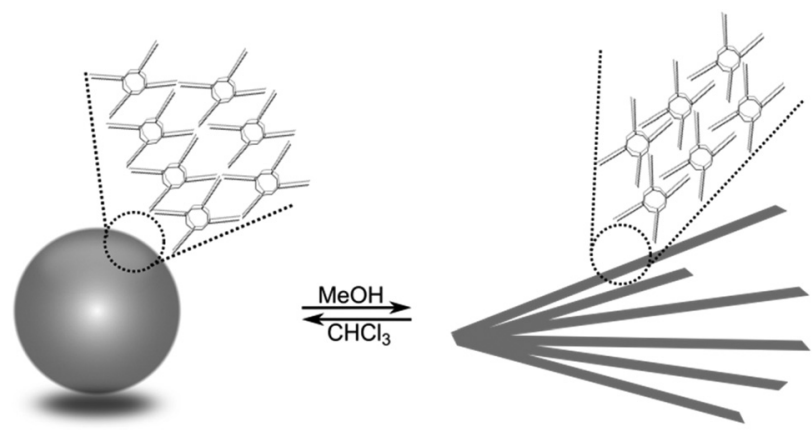

Fig. 12 Self-assembly depending on the solvent use.

series of parameters, such as the nature of the solvent, its polarity, and its concentration.

The nature of the solvent was admitted as a clue for the determination of the self-assembled morphologies, especially on the basis of its polarity and concentration. In the case of 2 , the self-assembly protocol was performed in a mixture of $\mathrm{MeOH} / \mathrm{CHCl}_{3}$ at different concentrations, at which the POSS moiety could be well dissolved and para-bromo-substituted POSS could form aggregates through $\mathrm{Br} \cdots \mathrm{Br}$ halogen bonds. The self-assembled morphologies were characterized by TEM (Fig. 11). In chloroform, the spherical morphology was obtained. The diameter of the spheres is around $50 \mathrm{~nm}$ (Fig. 11A). When the solvent was changed to methanol, diffused assembled rods were formed from the solution at a concentration of $5 \times 10^{-5} \mathrm{M}$ (Fig. 11B). The diffused rods grew from a central origin and became sharper (with $100 \mathrm{~nm}$ length); this also occurred during crystal formation. Thus, 2 tends to form a crystal morphology at a high concentration in methanol. Based on the results obtained from the TEM images, the assembled morphologies of 2 were greatly dependent on the nature of the assembly solution (Fig. 12).

\section{Reduction of imine-POSS to secondary amine-POSS}

Octa(aminopropylsilsesquioxane) is a very important precursor for many other hybrid organic/inorganic POSS because of the reactivity of its amine groups. Unfortunately, it is unstable in water, which can lead to the cleavage of its siloxane cage (Scheme 3).

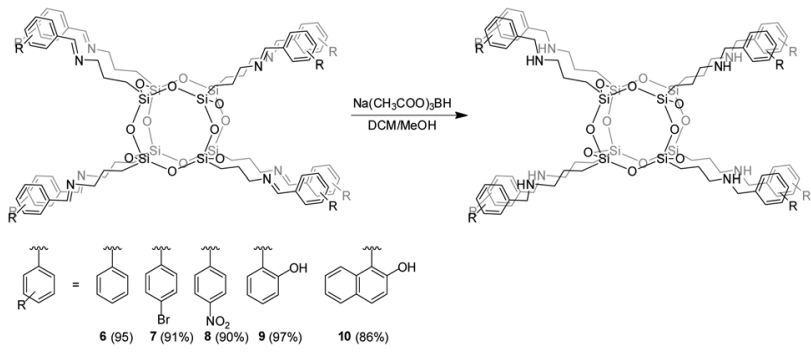

Scheme 4 Synthesis of secondary amine-POSS 6-10 via reduction of imine-POSS in the presence of $\mathrm{Na}\left(\mathrm{CH}_{3} \mathrm{COO}\right)_{3} \mathrm{BH}$.

In order to obtain secondary amine-POSS 6-10, starting from their imine-derivatives $\mathbf{1 - 5}$, sodium triacetoxyborohydride was used as a reducing agent (Scheme 4). POSS containing secondary amino fragments can be obtained in the reaction of nucleophilic substitution of octakis(3-chloropropyl) octasilsesquioxane POSS $^{35}$ with aniline, but in this method, the final product was synthesized with a low yield and the reaction required high temperatures $\left(110^{\circ} \mathrm{C}, 24 \mathrm{~h}\right)$. As mentioned above, such reactions are usually accompanied by cagerearrangement. From this perspective, the development of alternative synthetic pathways for secondary amine-POSS is extremely important. It should be noted that POSS with organic primary amines due to high basicity are unstable compounds in solution. ${ }^{24,25}$ The approach presented in this paper can be conducted under mild, anhydrous conditions (it does not require heating), and - what is its most important advantage - it does not lead to the formation of cage-reorganized products when using $\mathrm{Na}\left(\mathrm{CH}_{3} \mathrm{COO}\right)_{3} \mathrm{BH}$ as a reducing agent. The obtained compounds were characterized by multinuclear NMR $\left({ }^{1} \mathrm{H},{ }^{13} \mathrm{C}\right.$ and $\left.{ }^{29} \mathrm{Si}\right)$, FT-IR, UV-Vis, and HR-MS. It is worth noting that no siloxane cage decomposition was observed, as was clearly confirmed by mass spectrometry. It was investigated whether replacing the primary amine end groups by secondary amines could lead to an improvement in the water stability of the Si/O framework. Stability in the basic water solution was monitored by ${ }^{29} \mathrm{Si} \mathrm{NMR}$, and we did not observe any cage decomposition for 6-10.

After the reduction process, the signal derived from the imine moiety disappears in the ${ }^{1} \mathrm{H}$ NMR spectra of $\mathbf{6}$, and a new signal appears at $\delta=3.77 \mathrm{ppm}$, which can be assigned to the $\mathrm{PhCH}_{2} \mathrm{~N}$ group (see ESI, Fig. S40†). The progress of the reduction can be effectively monitored by both FT-IR and UV-Vis (Fig. 13) spectroscopy techniques. In the UV-Vis spectra, the absorption bands at 316 and $416 \mathrm{~nm}$, attributed to azomethine, disappear after the reduction, and the benzene ring ( $\pi-\pi^{*}$ transitions) produces bathochromic shifts from 255 to $278 \mathrm{~nm}$ after this process.

\section{Enol-imine to keto-enamine tautomerization}

It should be noted that the structures in the solid state may be different from those shown in solution, thereby complicating unequivocal assignments. Understanding proton tautomerization is of fundamental importance, not only in evaluating the 


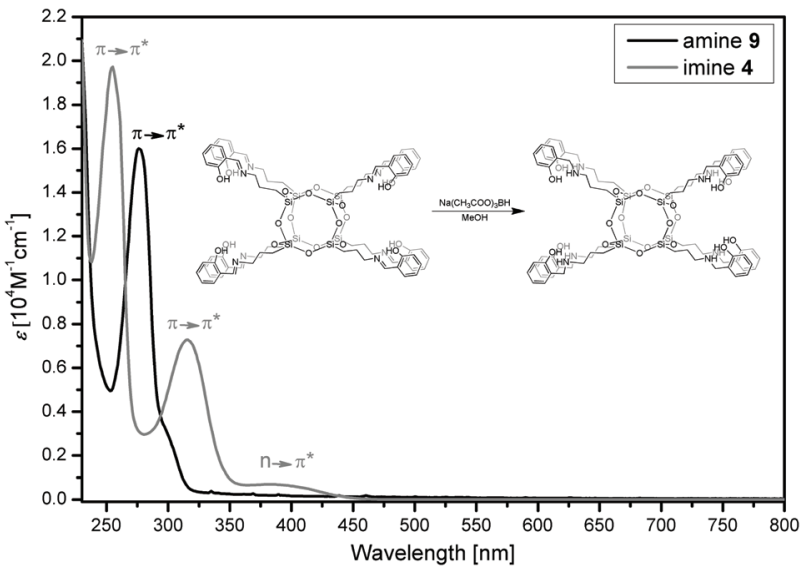

Fig. 13 Electronic absorption spectra (dichloromethane) for 4 and 9.

structural and/or electronic parameters involved in this behavior, but also for its potential application in the design of molecular switches in which Schiff bases can serve as valuable sensors. Studies on 2-hydroxy-substituted Schiff bases are interesting due to the appearance of the enol-imine and ketoenamine tautomerization. Such transformations are well documented in the literature both in solution and the solid state. The position of the proton in the $-\mathrm{OH} \cdots \mathrm{N}$ - tautomeric equilibrium significantly affects the physical, chemical, and biological properties of $o$-hydroxy Schiff bases. In general, imines are more stable than enamines, and a change in the tautomer population can be correlated with room-temperature thermochromism, whereas fluorescence is usually responsible for this phenomenon at lower temperatures. Most $o$-hydroxy Schiff bases (90\%) exist in the crystalline state in a neutral enolimine form. ${ }^{36,37}$ There is usually a rapid equilibrium in solution between imine and enamine (or zwitterionic) tautomers. Compound 5 exhibits a zwitterionic form in the solid state, whereas its keto-enamine and imine tautomers occur in solution. Keto-enol tautomerization and the migration of hydrogen from oxygen to nitrogen to form enamine or zwitterionic tautomers have been studied by UV-Vis and NMR spectroscopy.

Like in the solid state, thermochromism induced by proton transfer can also be observed in solution. ${ }^{38}$ The electronic absorption spectra were recorded in both polar methanol and non-polar dichloromethane and tetrachloromethane (Fig. 14). There is a complex band localized at $350-450 \mathrm{~nm}$ and assigned to ketone or enol forms. The absorption band localized at $400 \mathrm{~nm}$ confirms the presence of a keto-enamine form (orange in color) and derives from a naphthoquinone group, whereas the band at $420 \mathrm{~nm}$ indicates the presence of an enolimine form (yellow-green in color).

Imines show two singlets in their ${ }^{1} \mathrm{H}$ NMR spectra: one deshielded signal $(\delta \approx 13-15 \mathrm{ppm}$ ), corresponding to the phenol proton involved in intramolecular hydrogen bonding, and the other shifted upfield $(\delta \approx 8-9 \mathrm{ppm})$, which can be ascribed to the imine proton. On the other hand, enamines exhibit two coupled doublets: the deshielded $(\delta \approx 14-16 \mathrm{ppm})$

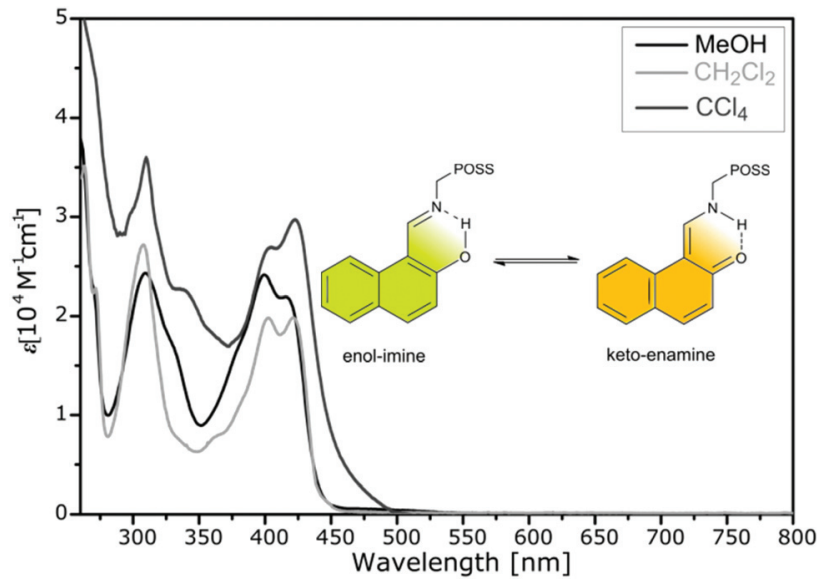

Fig. 14 Electronic absorption spectra for 5 recorded in different solvents $(298 \mathrm{~K})$.

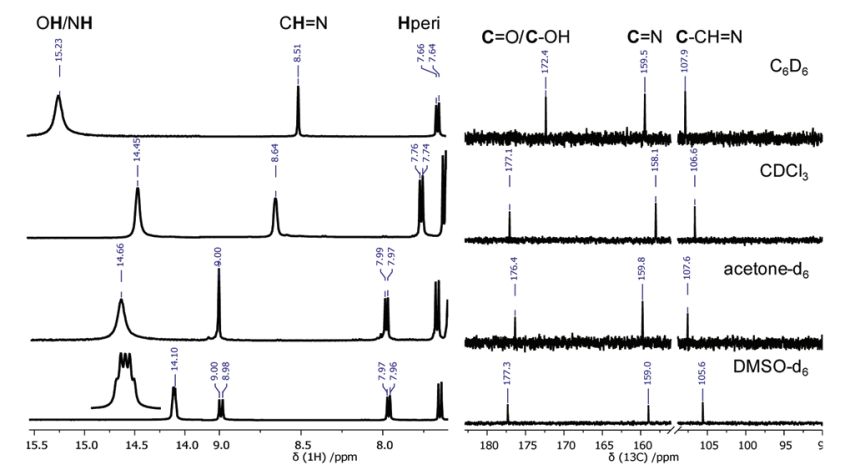

Fig. $15{ }^{1} \mathrm{H}$ and ${ }^{13} \mathrm{C}$ NMR spectra for 5 recorded for different solvent polarities.

$\mathrm{NH}$ proton involved in intramolecular hydrogen bonding, and the ethylene proton appearing in the range $\delta \approx 8.5-10 \mathrm{ppm}$. Although chemical shifts are similar in both tautomers, the multiplicity of such signals is the key to distinguishing them.

In a non-polar solvent $\left(\mathrm{CDCl}_{3}\right)$, signals derived from $\mathrm{CH}=\mathrm{N}-$ and $\mathrm{OH}$ groups constitute singlets localized at $\delta=$ 8.64 and $14.45 \mathrm{ppm}$, whereas, in a polar solvent (DMSO), a doublet of triplets at $\delta=14.10\left({ }^{3} J_{N H, H}=10.1,{ }^{1} J_{N, H}=5.0 \mathrm{~Hz}\right)$ ppm and a doublet at $\delta=7.96\left({ }^{3} J_{H H}=8.3 \mathrm{~Hz}\right)$ ppm occur and can be assigned to the $=\mathrm{CH}-\mathrm{NH}$ fragment (Fig. 15).

\section{Thermal properties}

Compared with conventional organic systems, organic-inorganic hybrid materials possess much more attractive thermal and mechanical properties and constitute one of the best solutions to enhance the features of materials. ${ }^{24,27}$ The thermal properties of 1-6 were examined by thermogravimetric analysis (TG-DTA) performed under air and dinitrogen and by differential scanning calorimetry (DSC) under anaerobic conditions (He). The TG-DTA data are collected in Table S15† (see also ESI, Fig. S4-S13†). The thermal stability of POSS is 
observed even at $300{ }^{\circ} \mathrm{C}$ but varies considerably depending on the stability of the organic group. The most detrimental substituents are nucleophilic groups, such as amines, which aid the breaking of siloxane bonds, particularly at higher temperatures. $^{39}$

TG curves of thermal decompositions are typical of functionalized polyhedral oligomeric silsesquioxanes, where two marked weight losses are observed. The first weight loss is related to the decomposition of organic side chains, and the second one relates to the decomposition of the siloxane cage to $\mathrm{SiO}_{2}$ in air. ${ }^{27}$ The percentage of the residue after thermolysis stays in agreement with the accuracy of $0.2 \%$ of the theoretically calculated mass for the formation of silicon dioxide. This confirms a purity of at least $99.8 \%$ and excludes contaminants derived from inorganic compounds used or accidentally obtained during decomposition. Furthermore, on the basis of $T_{5 \%}$ values, we evaluated the so-called thermal stability, which was observed in the range of $270-306{ }^{\circ} \mathrm{C}$. The lowest stability measured in the air atmosphere is noted for 3 , whereas 4 seems to be the most stable. The thermal stability in the $\mathrm{N}_{2}$ atmosphere is in turn slightly higher, by about $10^{\circ} \mathrm{C}$.

In the case of 2 , the observed residue is $25.82 \%$, whereas the calculated amount is $21.68 \%$. This difference is due to the incorporation of a halogen atom into the structure of silicon dioxide. The presence of halogen contamination was confirmed by EDS studies (see ESI, Fig. S71†).

Thermal measurements (decomposition to $\mathrm{SiO}_{2}$ ) were carried out both in synthetic air and under a dinitrogen atmosphere to confirm the participation of oxygen in the second stage of the degradation. Only in the case of measurements conducted in air did the calculated and the experimental values stay in agreement. For $\mathbf{1}$ and $\mathbf{3 - 5}$, decompositions carried out under both atmospheres are characterized by two significant weight losses, whereas, for 2 , three weight losses are observed. Additional weight losses are related to much more complex thermal transformations that can occur on organic arms. Generally, the thermal stability in $\mathrm{N}_{2}$ is higher than that observed under aerobic conditions.

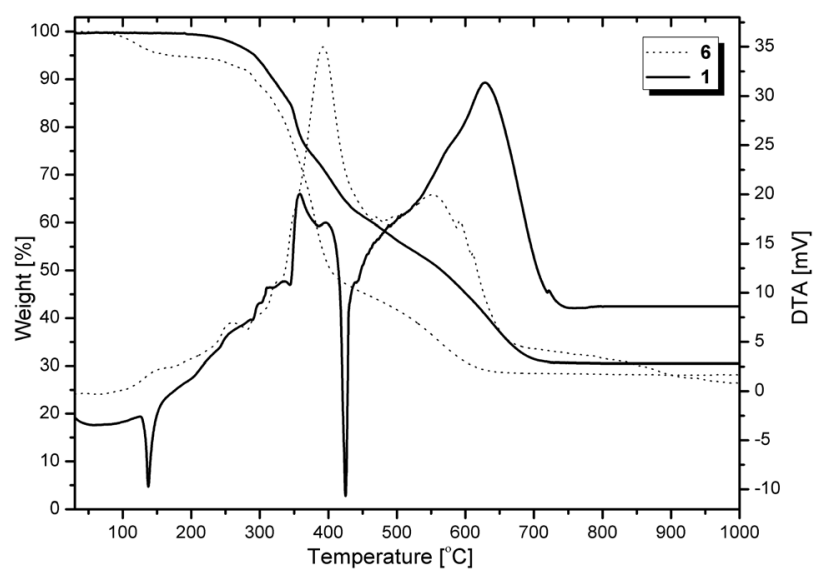

Fig. 16 TG-DTA (air) diagram for imino-functionalized POSS (solid line) and its amino-derivative (dotted line).
For imine 1-5, endothermic peaks are noticed in the DTA curves (straight curve in the TG diagram) and derived from the melting point. This is opposite to $\mathbf{6 - 1 0}$, where such a phenomenon was not observed (for amine-POSS, melting occurred simultaneously with decomposition). To confirm this, DSC studies were carried out and proved a phase transformation that was a melting point. Consequently, we assigned the melting and freezing temperatures. Imine derivatives exhibit the highest thermal stability compared to their amino analogues. For instance, $T_{5 \%}$ of the benzimine-substituted POSS derivative is $292{ }^{\circ} \mathrm{C}$, whereas the value for its secondary amine analogue is $167^{\circ} \mathrm{C}$ (Fig. 16).

\section{Conclusions}

In this study, we present a new synthetic approach for iminePOSS under mild conditions, in air and at room temperature. Our studies were concentrated on diverse groups of compounds possessing aryl sizable side chains with hydroxyl, nitro, and halide substituents. In the above studies, we have shown that imine-POSS can be effectively reduced to secondary amine-POSS under mild, anhydrous conditions, with no heating, and - what is the most important advantage - without the formation of cage reorganization products. It was investigated whether replacing the primary amine end groups by secondary amines could lead to an improvement in the water stability of the Si/O framework. We also successfully solved five crystal structures of imine-POSS, which might be considered a great achievement taking into account that few structures of functionalized polyhedral oligomeric silsesquioxanes are known in the literature. The performed studies also proved that a reaction between an OAS-POSS-Cl salt and an appropriate aldehyde leads to compounds in which enol-imine to keto-enamine tautomerization occurs. Thermal properties examined using TG-DTA and DSC studies showed that the thermal stability of imine-POSS can be observed even at $300{ }^{\circ} \mathrm{C}$, but it strictly depends on the nature of the side groups and the stability of these organic fragments. The lowest stability was noticed for 3, whereas 4 seems to be the most stable derivative. Imine-POSS also constitutes a perfect example for the study of a self-assembly protocol. Here, we described that the nature of the solvent can be admitted as a clue for the determination of the self-assembled morphologies, especially on the basis of the polarity of the solvent. To conclude, in this paper, we intended to discuss studies aimed at setting the stage for the design of tailored materials. With the presented structure-property relationships, open structures for infiltration, sequestration, or "guest-host" materials can be targeted.

\section{Acknowledgements}

This work was supported by the National Science Centre, Poland (Grant No. 2013/09/D/ST8/03995). 


\section{Notes and references}

1 M. F. Roll, P. Mathur, K. Takahashi, J. W. Kampf and R. M. Laine, J. Mater. Chem., 2011, 21, 11167-11176.

2 V. R. Reichert and L. J. Mathias, Macromolecules, 1994, 27, 7015-7023.

3 V. R. Reichert and L. J. Mathias, Macromolecules, 1994, 27, 7030-7034.

4 M. W. Lee, O. K. Farha, M. F. Hawthorne and C. H. Hansch, Angew. Chem., Int. Ed., 2007, 46, 30183022 .

5 O. K. Farha, R. L. Julius, M. W. Lee, R. E. Huertas, C. B. Knobler and M. F. Hawthorne, J. Am. Chem. Soc., 2005, 127, 18243-18251.

6 P. E. Eaton, E. Galoppini and R. Gilardi, J. Am. Chem. Soc., 1994, 116, 7588-7596.

7 P. E. Eaton, K. Pramod, T. Emrick and R. Gilardi, J. Am. Chem. Soc., 1999, 121, 4111-4123.

8 C. Eaborn and P. D. Lickiss, J. Organomet. Chem., 1985, 294, 305-313.

9 C. Sanchez, G. J. de A. A. Soler-Illia, F. Ribot, T. Lalot, C. R. Mayer and V. Cabuil, Chem. Mater., 2001, 13, 30613083.

10 C. Mellot-Draznieks, S. Girard and G. Férey, J. Am. Chem. Soc., 2002, 124, 15326-15335.

11 R. E. Morris, J. Mater. Chem., 2005, 15, 931-938.

12 R. M. Laine, J. Mater. Chem., 2005, 15, 3725-3744.

13 D. B. Cordes, P. D. Lickiss and F. Rataboul, Chem. Rev., 2010, 110, 2081-2173.

14 S.-W. Kuo and F.-C. Chang, Prog. Polym. Sci., 2011, 36, 1649-1696.

15 M. E. Pérez-Ojeda, B. Trastoy, Í. López-Arbeloa, J. Bañuelos, Á. Costela, I. García-Moreno and J. L. Chiara, Chem. - Eur. J., 2011, 17, 13258-13268.

16 K. L. Chan, P. Sonar and A. Sellinger, J. Mater. Chem., 2009, 19, 9103-9120.

17 M. F. Roll, J. W. Kampf and R. M. Laine, Macromolecules, 2011, 44, 3425-3435.

18 X. Yang, J. D. Froehlich, H. S. Chae, B. T. Harding, S. Li, A. Mochizuki and G. E. Jabbour, Chem. Mater., 2010, 22, 4776-4782.

19 T. Jaroentomeechai, P. Yingsukkamol, C. Phurat, E. Somsook, T. Osotchan and V. Ervithayasuporn, Inorg. Chem., 2012, 51, 12266-12272.

20 X.-D. Li, H.-P. Zang, J.-T. Wang, J.-F. Wang and H. Zhang, J. Mater. Chem. A, 2014, 2, 18554-18561.
21 I.-H. Chiang, W.-T. Chuang, C.-L. Lu, M.-T. Lee and H.-C. Lin, Chem. Mater., 2015, 27, 4525-4537.

22 C. Di Iulio, M. D. Jones and M. F. Mahon, J. Organomet. Chem., 2012, 718, 96-100.

23 C. Di Iulio, M. D. Jones, M. F. Mahon and D. C. Apperley, Inorg. Chem., 2010, 49, 10232-10234.

24 M. Janeta, Ł. John, J. Ejfler and S. Szafert, Chem. - Eur. J., 2014, 20, 15966-15974.

25 F. J. Feher, K. D. Wyndham, D. Soulivong and F. Nguyen, J. Chem. Soc., Dalton Trans., 1999, 14911498.

26 Y. El Aziz, A. R. Bassindale, P. G. Taylor, R. A. Stephenson, M. B. Hursthouse, R. W. Harrington and W. Clegg, Macromolecules, 2013, 46, 988-1001.

27 M. Janeta, Ł. John, J. Ejfler and S. Szafert, RSC Adv., 2015, 5, 72340-72351.

28 J. C. Furgal, T. G. Iii and R. M. Laine, Dalton Trans., 2016, 45, 1025-1039.

29 S. Chimjarn, R. Kunthom, P. Chancharone, R. Sodkhomkhum, P. Sangtrirutnugul and V. Ervithayasuporn, Dalton Trans., 2015, 44, 916-919.

30 V. Ervithayasuporn and S. Chimjarn, Inorg. Chem., 2013, 52, 13108-13112.

31 A. R. Bassindale, Z. Liu, I. A. MacKinnon, P. G. Taylor, Y. Yang, M. E. Light, P. N. Horton and M. B. Hursthouse, Dalton Trans., 2003, 2945-2949.

32 M. F. Roll, J. W. Kampf and R. M. Laine, Cryst. Growth Des., 2011, 11, 4360-4367.

33 T. Sekikawa, T. Kobayashi and T. Inabe, J. Phys. Chem. A, 1997, 101, 644-649.

34 R. F. Childs, G. S. Shaw and C. J. Lock, J. Am. Chem. Soc., 1989, 111, 5424-5429.

35 M. Dutkiewicz, H. Maciejewski and B. Marciniec, Synthesis, 2009, 2019-2024.

36 P. M. Dominiak, E. Grech, G. Barr, S. Teat, P. Mallinson and K. Woźniak, Chem. - Eur. J., 2003, 9, 963-970.

37 R. F. Martínez, M. Ávalos, R. Babiano, P. Cintas, J. L. Jiménez, M. E. Light and J. C. Palacios, Eur. J. Org. Chem., 2011, 3137-3145.

38 W. Schilf, B. Kamieński, B. Kołodziej and E. Grech, J. Mol. Struct., 2004, 708, 33-38.

39 Applications of Polyhedral Oligomeric Silsesquioxanes, ed. C. Hartmann-Thompson, Springer, Netherlands, Dordrecht, 2011, vol. 3.

40 Ł John, M. Janeta, M. Rajczakowska, J. Ejfler, D. Łydżba and S. Szafert, RSC Adv., 2016, 6, 66037-66047. 